\title{
Foreword
}

\section{Marc Maresceau}

This project on legal aspects of bilateral migration issues is the result of a fascinating and particularly stimulating synergy of a great variety of initiatives and commitments which occurred and developed in a complex and very quickly changing international environment. It is therefore worthwhile recalling the origins of what is now the book in front of us. It might indeed be surprising, certainly for a non-Italian, and perhaps also for an Italian, observer, that it was the Regione Autonoma della Sardegna which, in a truly visionary approach, in 2010, that is well before the outbreak of the big migration crisis, decided that an academic research project could be supported on 'Bilateral Relations in the Mediterranean: Prospects for Migration Issues'. It is indeed very likely that without the decision of the regional authority of Sardinia, there would not have been a book on bilateral approaches to migration in the Mediterranean. The main purpose of the project, as initially conceived, was to attempt to shed light in the labyrinth of the increasing number initiatives taken from the EU and Member States in this field.

While it was obvious and natural that the University of Cagliari would play the leading role in the project's academic management, it also rapidly became clear that, because of the nature, size and scope of the project, it was justified to broaden academic coordination and to bring in another Italian university. In light of the expertise on EU external relations law, which such a project necessarily entails, it was thought that coordination input could best be co-organized with the University of Bologna. The joint character of this undertaking is also well reflected in the editorial team, responsible for the publication of the book, which includes distinguished colleagues from the universities of Cagliari and Bologna.

At first sight, the conceptual structure of a project on bilateral approaches on migration issues in the Mediterranean looked simple and evident on paper: on the one hand bilateral national approaches which, for the purposes of this book, meant the approaches of the EU Member States, and on the other hand those of the EU itself needed to be analysed and possible interactions between these two approaches examined. In order to perform this task properly, legal experts from forefront States, such as Spain, Greece, Malta, Italy and France, were contacted and their contributions constitute an in-depth analytical and 
comparative legal overview of these national practices. The second and third parts of this book focus on EU bilateral relations regarding migration in the Mediterranean and on specific horizontal issues on migration management. International law and EU law experts have contributed and their contributions provide a solid insight and guide in this not always clear and transparent area of EU external relations law. However, practice also shows, as is clearly demonstrated in many of the contributions in this book, that the coexistence and interaction between national bilateral approaches and the EU bilateral approach are a highly complex and sensitive political and legal matter. As an illustration it may suffice to refer to the pivotal question of 'readmission', which comes up in most of the contributions in this book.

No doubt, in the genesis of this volume, the international conference organized on 12 June 2015 at the University of Cagliari, constituted a crucial momentum. The main purpose of this gathering was to report on the progress of the research undertaken and this stocktaking also offered the opportunity to identify a number of additional research questions which deserved to be further explored. Furthermore, 2015 was also the year in which the migration crisis in the Mediterranean and in the EU, reached its zenith and Chancellor Merkel's famous statement 'Wir schaffen das' came just two and a half months after the Cagliari conference. Needless to say that this and other further developments since that conference, such as the EU-Turkey Statement of 18 March 2016, the aftermath of the failed coup d'état in Turkey, the development of the crisis in Syria and Libya have all seriously affected the course of preparation of this book. Fortunately, the editors and contributors alike were courageous enough to persevere, and the result of this unwavering commitment is the book for which I have now the privilege to write the preface.

Ghent, 1 February 2020

Prof. Marc Maresceau

Jean Monnet Chair ad personam, Ghent University Visiting professor College of Europe, Bruges and Natolin 